\title{
Ruptured rudimentary horn pregnancy of unicornuate uterus: a case report
}

\section{Lopamudra Jena*, Rabi Narayan Satapathy, Sujata Swain, Purna Chandra Mahapatra}

Department of Obstetrics \& Gynaecology, S C B Medical College, Cuttack, Odisha, India

Received: 13 November 2014

Accepted: 19 December 2014

\author{
*Correspondence: \\ Dr. Lopamudra Jena, \\ E-mail: julijena82@gmail.com
}

Copyright: (c) the author(s), publisher and licensee Medip Academy. This is an open-access article distributed under the terms of the Creative Commons Attribution Non-Commercial License, which permits unrestricted non-commercial use, distribution, and reproduction in any medium, provided the original work is properly cited.

\begin{abstract}
Unicornuate uterus with rudimentary horn occurs due to failure of complete development of one of the Mullerian ducts and incomplete fusion with the contralateral side. Pregnancy in the noncommunicating rudimentary horn is extremely rare and usually terminates in rupture during first or second trimester of pregnancy. Pregnancy occurs via transperitoneal migration of sperm or zygote. Variable thickness of rudimentary horn musculature, poor distensibility of myometrium lead to rupture. This complication is usually seen in $2^{\text {nd }}$ trimester resulting in shock and haemoperitoneum. Diagnosis of rudimentary horn pregnancy is difficult and can be missed in ultrasound. It requires a high risk of suspicion. We report a case of G2A1 with pregnancy of 20 weeks gestation which was suspected as intraabdominal pregnancy on ultrasound and on laparotomy a live fetus of 19 weeks in intact gestational sac was found in ruptured left noncommunication horn of unicornuate uterus with haemoperitoneum. Timely laparotomy, excision of the horn and blood transfusion saved the patient.
\end{abstract}

Keywords: Rudimentary horn, Unicornuate uterus, Haemoperitoneum

\section{INTRODUCTION}

Mullerian anomalies were first classified in 1979 by Buttram and Gibbons and further revised by the American Society of Reproductive Medicine in 1988. Unicornuate uterus is a type 2 classification with unilateral hypoplasia or agenesis that can be further subclassified into communicating, noncommunicating, no cavity, and no horn. ${ }^{1}$ The incidence of uterine congenital anomalies because of Mullerian defects in the normal fertile population is $3.2 \%$. A unicornuate uterus accounts for $2.4 \%-13 \%$ of all Mullerian anomalies. ${ }^{2} 72-85 \%$ of the rudimentary horns are noncommunicating with the cavity. ${ }^{3}$ Unicornuate uterus with rudimentary horn may be associated with gynaecological and obstetric complications like infertility, endometriosis, haematometra, urinary tract anomalies, abortions, and preterm deliveries. Rupture during pregnancy is the most dreaded complication which can be life threatening to the mother. We report a case of ruptured rudimentary horn pregnancy of 20 weeks gestation which was ultrasonographically diagnosed as intra-abdominal pregnancy and on laparotomy was managed by resection of the rudimentary horn.

\section{CASE REPORT}

A 21-year-old G2A1 with amenorrhoea of five months was referred from district head quater hospital with complains of pain abdomen for two days which gradually increased in intensity, was more in the lower abdomen and associated with vomiting and one episode of syncopal attack. She was married for 3 years and had a spontaneous first trimester abortion one year back. Her menstrual cycles were regular. On admission patient had mild pallor, no icterus, pulse rate was $96 / \mathrm{min}$, blood pressure - $100 / 60 \mathrm{~mm}$ of $\mathrm{Hg}$ and respiratory rate was 20/min. On abdominal examination there was generalised 
tenderness, with guarding and uterus was 20 weeks size. Per speculum examination showed no vaginal bleeding, on per vaginal examination there was a boggy mass in the right fornix, left fornix and POD were free with no cervical motion tenderness. Ultrasound in district head quater showed mild to moderate ascites, an anteverted bulky uterus with uniform myometrial echoes. There was evidence of intra-abdominal live foetus of 19 to 20 weeks gestation on right side. Uterus measures $9.30 \times 5.30 \times$ $5.40 \mathrm{~cm}$. Patient was managed conservatively for one day and repeat ultrasound was done which showed single live extra-uterine pregnancy of AGA 18 week 5 days with weight $-258 \pm 38$ gm and placenta - grade-0 with free fluid in peritoneal cavity. So laparotomy was planned anticipating intra-abdominal pregnancy with haemoperitoneum. On laparotomy there was haemoperitoneum. There was a partial ruptured noncommunicating horn of uterus on the left side of the uterus with live fetus in intact gestational sac protruding through the rent (Figure 1). Left fallopian tube and ovary were attached to the non-communicating horn right fallopian tube \& ovary were healthy \& attached to the uterus (Figure 3). Then the non-communicating horn containing the fetus of approx 20 weeks and placenta along with left tubes were resected out using vessel sealer (Figure 2, 5). Left ovary, right tube \& ovary left in situ. Haemostatic sutures with vicryl 1-0 was given in the resected margin of uterus (Figure 4). Post operatively patient was transfused with on unit of blood and here recovery was uneventful. She was discharged on $8^{\text {th }}$ postoperative day.

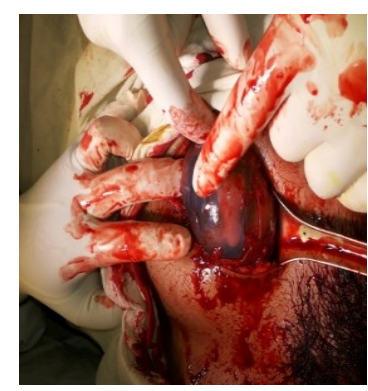

Figure 1: Live fetus in side the intact gestational sac present in the partially ruptured non-communicating horn of uterus.

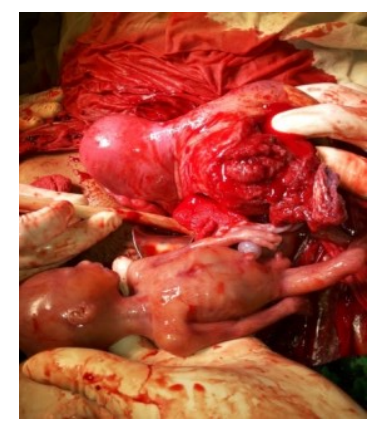

Figure 2: Anterior view showing uterus, noncommunicating horn along with placenta, cord \& foetus.

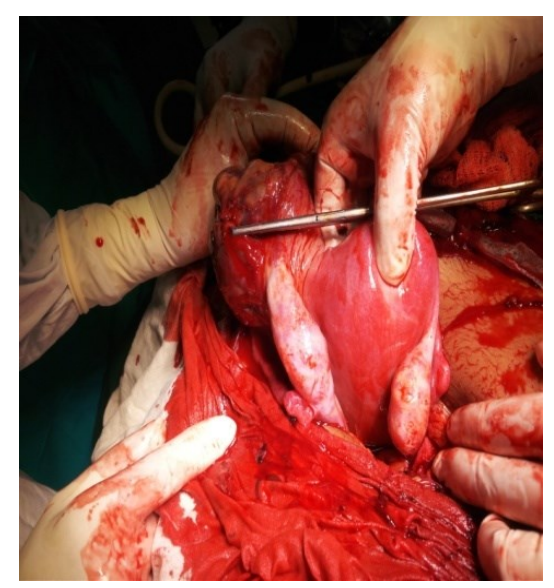

Figure 3: Posterior view showing uterus, noncommunicating horn along with both the ovaries.

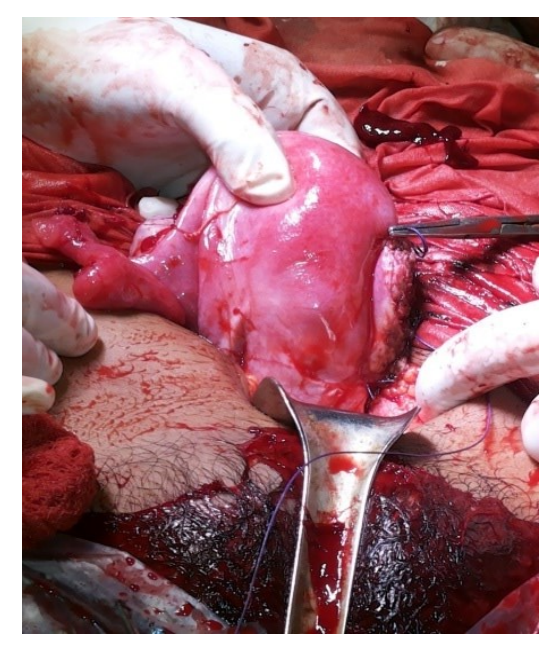

Figure 4: Anterior view showing uterus along with right fallopian tube.

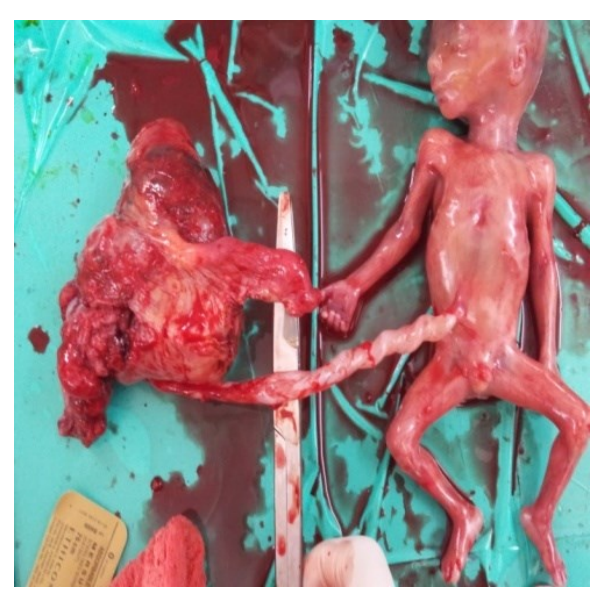

Figure 5: Non-communicating horn along with placenta, cord, baby \& left fallopian tube.

\section{DISCUSSION}

A rudimentary horn with a unicornuate uterus results due to failure of the complete development of one of the 
Mullerian ducts and incomplete fusion with the contralateral side. The incidence is estimated at 1 per 100000 to 140000 pregnancies. $^{3}$ Pregnancy in a noncommunicating rudimentary horn occurs through the transperitoneal migration of the spermatozoon or the transperitoneal migration of the fertilized ovum. ${ }^{4}$ The first case of uterine rupture associated with rudimentary horn was reported in 1669 by Mauriceau. ${ }^{5}$ The timing of rupture varies from 5 to 35 weeks depending on the horn musculature and its ability to hypertrophy and dilate. 70$90 \%$ rupture before 20 weeks and can be catastrophic. ${ }^{6}$ As the uterine wall is thicker and more vascular, bleeding is more severe in rudimentary horn pregnancy rupture. Kadan and Romano described rudimentary horn rupture as the most significant threat to pregnancy and a lifethreatening situation. ${ }^{8}$ Early diagnosis of the condition is essential and can be challenging. Ultrasound, hysterosalpingogram, hysteroscopy, laparoscopy, and MRI are diagnostic tools. ${ }^{9}$ Fedele et al. have found ultrasonography to be useful in the diagnosis. ${ }^{10}$ But the sensitivity of ultrasound is only $26 \%$ and sensitivity decreases as the pregnancy advances. ${ }^{11}$ It can be missed in inexperienced hands as in our case. Tubal pregnancy, cornual pregnancy, intrauterine pregnancy, and abdominal pregnancy are common sonographic misdiagnosis.

Tsafrir et al. reported 2 cases of rudimentary horn pregnancy found in the first trimester by sonography and confirmed by MRI. They outlined a set of criteria for diagnosing pregnancy in the rudimentary horn. ${ }^{12}$ They are (1) a pseudo pattern of asymmetrical bicornuate uterus; (2) absent visual continuity tissue surrounding the gestation sac and the uterine cervix; (3) presence of myometrial tissue surrounding the gestational sac. Nonetheless, most of the cases remain undiagnosed until it ruptures and present as emergency. Cases of late and false diagnosis leading to uterine rupture have been reported. Use of labor induction agents for termination of pregnancy in a rudimentary horn is unsuccessful and can lead to rupture of the horn. Nonresponders to induced abortion should be investigated with a high index of suspicion. Buntungu et al. reported a rudimentary horn pregnancy in a $6^{\text {th }}$ gravida with all previous normal deliveries with a diagnosis of intrauterine fetal demise in this pregnancy where induction with misoprostol failed leading to the suspicion of ectopic pregnancy. ${ }^{13}$

Primary strategy of management of rudimentary horn is surgical removal. Immediate surgery is recommended by most after the diagnosis even in unruptured cases. Removal of the horn prior to pregnancy in order to prevent complications is also advised. However, conservative management, until viability is achieved, has been advocated in few selected cases if emergency surgery can be performed anytime and if the patient is well informed. A case of pregnancy progressing to the third trimester and resulting in live birth after caesarean section has been documented. ${ }^{14}$

\section{CONCLUSION}

Despite advances in ultrasound and other diagnostic modalities, prenatal diagnosis remains elusive, with confirmatory diagnosis being laparotomy. The diagnosis can be missed in ultrasound especially in inexperienced hands. Precious time may be lost due to delay in diagnosis or misdiagnosis and the general condition of the person may worsen. Timely resuscitation, surgery, and blood transfusion are needed to save the patient. Proper diagnostic methods and early referral from the peripheral hospitals is needed to reduce the morbidity and mortality of the patients. There is a need for an increased awareness of this condition especially in developing countries where the possibility of detection before pregnancy or before the rupture is unlikely, and precious time is lost in shifting these women to the referral hospital.

\section{Funding: No funding sources \\ Conflict of interest: None declared \\ Ethical approval: Not required}

\section{REFERENCES}

1. Hassan CHC, Kadir A, Karim A, Ismail NAM, Omar $\mathrm{MH}$. Case report of ruptured non-communicating right rudimentary horn pregnancy: an acute emergency. Acta Medica, 2011;54(3):125-6.

2. Simon C, Martinez L, Pardo F, Tortajada M, Pellicer A. Mullerian defects in women with normal reproductive outcome. Fertil Steril. 1991;56(6):11923 .

3. Sevtap HK, Aral AM, Sertac B. An early diagnosis and successful local medical treatment of a rudimentary uterine horn pregnancy: a case report. Arch Gynaecol Obstet. 2007;275(4):297-8.

4. Scholtz M. A full-time pregnancy in a rudimentary horn of the uterus. $\mathrm{Br} \mathrm{J}$ Obstet Gynaecol. 1951;58:293-6.

5. Mauriceau F. Traite des maladaies des femmes grosses. In: Mauriceau F, eds. A Book. 1st ed. Paris, France: Compaigne des libraries; 1721.

6. O'leary JL, O'leary JA. Rudimentary horn pregnancy. Obstet Gynaecol. 1963;22:371-4.

7. Chowdhury S, Chowdhury T, Azim E. Pregnancy in a non-communicating rudimentary horn of uterus: a clinical case report. Bangladesh Med J. 2010;39(1):47-8.

8. Kadan Y, Romano S. Rudimentary horn pregnancy diagnosed by ultrasound and treated by laparoscopy: a case report and review of the literature. J Minim Invasive Gynaecol. 2008;15(5):527-30.

9. Lawhon BP, Wax JR, Dufort RT. Rudimentary uterine horn pregnancy diagnosed with magnetic resonance imaging. Obstet Gynaecol. 1998;91(5):869.

10. Fedele L, Dorta M, Vercellini P, Brioschi D, Candiani GB. Ultrasound in the diagnosis of 
subclasses of unicornuate uterus. Obstet Gynaecol. 1988;71(2):274-7.

11. Jayasinghe Y, Rane A, Stalewski H, Grover S. The presentation and early diagnosis of the rudimentary uterine horn. Obstet Gynaecol. 2005;105(6):1456-67.

12. Tsafrir A, Rojansky N, Sela HY, Gomori JM, Nadjari M. Rudimentary horn pregnancy: firsttrimester prerupture sonographic diagnosis and confirmation by magnetic resonance imaging. J Ultrasound Med. 2005;24(2):219-23.
13. Buntungu KA, Ntumy MY, Ameh EO, Obed SA. Rudimentary horn pregnancy: pre-rupture diagnosis and management. Ghana Med J. 2008;42(2):92-4.

14. Shin JW, Kim HJ. Case of live birth in a noncommunicating rudimentary horn pregnancy. J Obstet Gynaecol Res. 2005;31(4):329-31.

DOI: $10.5455 / 2320-1770$. ijrcog20150250

Cite this article as: Jena L, Satapathy RN, Swain S, Mahapatra PC. Ruptured rudimentary horn pregnancy of unicornuate uterus: a case report. Int J Reprod Contracept Obstet Gynecol 2015;4:259-62. 